\title{
La transferència de la formació permanent del professorat. Estudi de casos
}

\section{Joan Fuguet Busquets ${ }^{\mathrm{a}}$}

\author{
Data de defensa: $13 / 06 / 2014$
}

Paraules clau: formació, transferència, avaluació, reflexió i compromís

\section{Justificació}

La nostra experiència professional en la docència i en la direcció d'una escola d'Infantil i Primària, i sobretot en l'àmbit de la formació permanent com a assessor i formador del Departament d'Ensenyament i de l'Institut de Ciències de l'Educació de la Universitat Rovira i Virgili (URV), fa que tinguem la percepció que els esforços que es dediquen curs rere curs, per part dels equips de docents dels centres educatius, en l'elaboració i posterior participació en els plans de formació del professorat del centre i el cost econòmic dels recursos que s'inverteixen per part de l'Administració Educativa en la constitució i formació d'equips de formadors per tal que exerceixin la seva docència o assessorament en els centres educatius, no incideixen d'una manera prou eficaç i amb garanties de perdurabilitat en la pràctica docent a les aules.

L'interès en aquest camp ja ha tingut un precedent en la realització del treball de fi d'estudis del màster de "Formació de Professionals de la Formació", que tenia com a objectiu principal saber quina era la percepció que tenen els docents d'Infantil i Primària de dues escoles públiques de Tarragona sobre la transferència de la formació permanent a la seva pràctica educativa a l'aula i la incidència que tenia en el seu desenvolupament professional.

\section{Finalitat}

La investigació focalitza l'atenció a esbrinar com es produeix la transferència immediata i diferida de la formació permanent del professorat d'Infantil i Primària a la seva pràctica a l'aula, concretament a partir de la modalitat de formació en centre.

\footnotetext{
${ }^{a}$ Departament de Pedagogia. Universitat Rovira i Virgili - Tarragona
} 


\section{Objectius}

a) Analitzar els processos de detecció de necessitats de formació i de presa de decisions a l'hora de dissenyar el Pla de Formació de centre.

b) Detectar la influència que té l'acció formativa en el docent i en el canvi de les seves pràctiques educatives a l'aula.

c) Analitzar els factors que afavoreixen o obstaculitzen la transferència de la formació permanent a la pràctica educativa dels docents a l'aula.

d) Identificar quins protocols d'avaluació estableix el centre per determinar la transferència de la formació permanent.

\section{Metodologia}

Situem la investigació des d'un paradigma interpretatiu, ja que es pretén comprendre una realitat educativa i el seu interès se centra en el procés que s'ha seguit per copsar la realitat. En el nostre cas, és la gestió dels processos de formació permanent, on les percepcions de les persones, les accions i els significats que les acompanyen incideixen en la construcció de la realitat subjecta a processos de canvi. D'acord amb la informació que es pretén obtenir podem afirmar que la perspectiva metodològica és qualitativa, ja que va recollint les dades en un ambient natural i amb la utilització d'un llenguatge adequat a l'hora de fer les descripcions.

El mètode d'investigació és l'estudi de cas i nosaltres hem realitzat l'estudi de tres casos, dos ubicats en el "Centre (1)" i un tercer ubicat en el "Centre (2)" que es corresponen a tres accions formatives diferents, recollint a través de l'anàlisi documental tota la informació necessària sobre cadascuna d'elles. També s'ha recollit informació a través de les opinions emeses pels responsables de formació dels centres, pels formadors i pels docents participants utilitzant diferents instruments de recollida d'informació. En el seguiment dels diferents cursos de formació que s'han realitzat als centres, podem afirmar que tant l'investigador com els docents han demostrat una participació compartida. També s'ha establert un estil de treball amb una negociació inicial amb els directors dels centres estudiats i essent molt curosos amb la utilització de la informació i establint protocols de confidencialitat amb tots els actors que han intervingut en la investigació. Finalment, en la redacció de l'informe s'ha intentat ser molt accessibles a una audiència àmplia, encara que no sigui entesa en el tema.

\section{Conclusions}

Presentem les conclusions de l'estudi de les tres accions formatives, a partir dels objectius plantejats en el seu inici per tal d'intentar donar-hi resposta. 
En el procés d'estudi de necessitats i presa de decisions a l'hora d'elaborar el Pla Formació de centre s'han d'establir protocols on la participació del professorat tingui un paper molt rellevant, no només com a opinió individual, sinó com a partícips d'una organització que aprèn de la seva pròpia experiència i que crea el seu propi coneixement.

Per tal que la formació tingui una incidència més directa en les pràctiques que els docents realitzen a les aules, aquests han de tenir un paper protagonista en el procés de disseny i execució de les accions formatives. Els agents participants, formador, responsable i docents han d'establir quins són els objectius a assolir, quina serà l'organització dels recursos i quines activitats es realitzaran, en un marc de colllaboració conjunta que faci que els docents sentin que hi tenen un rol actiu que els faci sentir part inherent del procés. Cal, doncs, l'elaboració d'un discurs amb una proposta d'activitats que tinguin un component d'ajust a la realitat pel que fa a les possibilitats de dur-les a terme. També ha d'afavorir la creació, per part de tots els agents, d'expectatives d'èxit envers l'aprenentatge dels continguts de la formació i en l'assoliment dels objectius.

És molt important que en la cultura del centre s'instal.li la necessitat de transferir els aprenentatges assolits en la formació fent constar en el Pla de Formació el lideratge que ha d'exercir el seu responsable, recordant als docents les finalitats dels processos de formació i creant un feedback positiu en la comunicació entre els seus equips de treball. Hi ha coincidència en tots els agents que han participat en les tres accions formatives que un factor que influeix en la transferència de la formació és el suport que pot donar el formador al participant en el mateix lloc de treball en el procés de transferència dels continguts apresos, recollint evidències de la seva pràctica i ajustant els continguts treballats als imprevistos sorgits.

En el procés de disseny de l'acció formativa, proposar unes tasques a realitzar que siguin properes a les situacions que es donen en el lloc de treball i plantejar la resolució de situacions similars a les que es plantegen els professors en la seva activitat diària afavoreix els processos de transferència a l'aula.

La creença dels formadors sobre la poca influència que pot tenir la formació permanent en el canvi de les pràctiques professionals fa que les seves expectatives siguin baixes, i això pot influir a l'hora de la seva intervenció en l'acció formativa ajustant la seva proposta a resoldre situacions de caire més formal, i no a incidir en les creences professionals dels docents.

La motivació va molt lligada al grau d'incentivació que els docents poden percebre sobre el seu desenvolupament professional des de la vessant intrínseca, la necessitat d'alterar el seu coneixement, les seves creences i pràctiques professionals cap a un propòsit articulat que doni resposta a les necessitats de la comunitat educativa i des de la vessant extrínseca, els beneficis que els pot aportar aquest procés de canvi quant al desenvolupament de la seva carrera professional. 
Per poder verificar si la formació té una incidència en la manera d'actuar dels docents a les aules i en l'organització del centre, cal que els protocols que s'estableixin permetin recollir evidències dels canvis que es donen en la metodologia aplicada a les aules per part dels docents i en les estructures organitzatives del centre.

La motivació dels docents per transferir a les aules el que han après a la formació també ha d'anar acompanyada d'un cert reconeixement del docent, per part de l'Administració educativa, pel fet d'haver canviat la seva conducta en el lloc de treball, recollit en la definició de la carrera professional del docent que fa La Llei d'Educació de Catalunya (LEC).

\section{Bibliografia}

Baldwin, T. T. i Ford, J. K. (1988). Transfer of training: A review and directions for future research. Personnel Psychology, 41 (1), 63-105.

Bolivar, A. (2000). Los centros educativos como organizaciones que aprenden. Madrid: La Muralla.

-(2010). ¿Cómo un liderazgo pedagógico y distribuido mejora los logros académicos? Revisión de la investigación y propuesta. Revista Internacional de Investigación en Educación, 3 (5), 79-106.

Broad, M. L. i Newstrom, J. W. (1992). Transfer of Training. Action packed strategies to ensure high payoff from training investments. Reading, MA: Addison-Wesley.

Cheng, E.W.L. i Ho, D.C.K. (2001). A review of transfer of training studies in the past decade. Personnel review, 30 (1), 102-118.

Fullan, M. (1992). Successful school improvement: the implementation perspective and beyond. Philadelphia: Open University Press

-(2002a). Los nuevos significados del cambio en educación. Barcelona: Octaedro.

-(2002b). Las fuerzas del cambio: Explorando las profundidades de la reforma educativa. Madrid: Akal.

Fullan, M. i Hargreaves, A. (1997). ¿Hay algo por lo que merezca la pena luchar en la escuela? Sevilla: Publicaciones MCEP.

Gairín, J. (2010). La evaluación del impacto en programas de formación. Revista Iberoamericana sobre Calidad, Eficacia y Cambio en Educación, 8. Recuperat des de http://www.rinace.net/reice/numeros/arts/vol8num5/art1.pdef.

-(2012). Gestión del conocimiento y desarrollo organizativo: formación y formación corporativa. Madrid: Wolters Kluwer/ Educac.

Garavaglia, PL. (1998). La transferencia de la formación: ¿cómo consolidarla? Barcelona: EPISE, Formación \& Desarrollo. 
Guba, E.G. i Lincon, Y.S. (1991). Investigación naturalista y racionalista. Dins Husen T. i Postlethwaite, T.N., Enciclopedia internacional de la educación, 6, (pp. 3337-3343). Barcelona: Vicens-Vives.

Guskey, T. (2003). The characteristics of effective professional development. A synthesis of lists. Recuperat des d' ERIC ED 478380.

-(2003). Replantear el cambio educativo: un enfoque renovador. Buenos Aires: Amorrortu.

Hargreaves, A. i altres (1998). Una educación para el cambio. Reinventar la educación de los adolescentes. Barcelona: Octaedro.

Imbernon, F. (1987). La formació permanent del professorat: Anàlisi del formadors de formadors. Barcelona: Barcanova.

-(2007). La formación permanente del profesorado. 10 ideas clave. Barcelona: GRAO.

Iranzo, P. (2002). Formación del profesorado para el cambio: desarrollo profesional en cursos de formación $y$ en proyectos de asesoramiento en centros. Tesis doctoral. Recuperat des de htpp://tdx.cesca.es/TDCat-1204102-163449/.945pp.

-(2009). Innovando en educación. Formarse para cambiar: un viaje personal. Barcelona: Erasmus Ediciones- El Cobre.

-(2012). Asesoramiento pedagógico al profesorado. Madrid: Síntesis.

Kirkpatrick, D. i Kirkpatrick, J. (1999). Evaluación de acciones formativas. Los cuatro niveles. Barcelona: Epise: Gestión 2000 (3ª Edición).

-(2005). Como transferir el aprendizaje a la conducta. Barcelona: Epise.

Marcelo, C. (1994). Formación del profesorado para el cambio educativo. Barcelona: EUB.

-(1995). Desarrollo profesional o iniciación a la enseñanza. Barcelona: PPU.

-(2009). Professional Development of Teachers: past and future. Sísifo. Educational Sciences Journal. Vol. 8. Pp. 5-20. Recuperat des de http://sisifo.fpce.ul.pt.

-(2011). (Coord.). Evaluación del desarrollo profesional docente. Barcelona: Davinci.

Navio, A. (2005). Las competencias profesionales del formador. Barcelona: Octaedro.

Noe, R. (1986). Trainees' Attributes and Attitudes: Neglected Influences on Training Effectiveness. Academy of Management Review, 11 (4), 736-749.

Pineda, P. (2002). Evaluación de la formación en la organización. Dins de Pineda, P. (Coord,) Gestión de la formación en las organizaciones (pp. 241-289). Barcelona: Ariel.

-(2006). El nuevo modelo de formación continua en España: balance de un año de cambios. Revista de Educación, 341, 705-736. 
Pineda, P. i altres. (2009). Diagnóstico de los factores que afectan la transferencia del aprendizaje en 11 empresas españolas. [Informe técnico].

-(2011). Avaluació de la transferència de la formació a l'Administració pública de Catalunya. Escola d'Administració Publica. Generalitat de Catalunya.

Sarramona, J. (2002). La formación continua laboral. Madrid: Biblioteca Nueva.

Stake, R. E. (1998). Investigación con estudio de casos. Madrid: Morata.

Swanson, R. A. (1996). Evaluation systems in HRD. PLS evaluation system: Sales communication case study. Symposium Evaluation systems in HRD, 718-725.

Teixidó, J. (2005). El lideratge del canvi en els centres educatius. Departament d'Ensenyament. Generalitat de Catalunya. V Jornada de la qualitat de l'ensenyament. Recuperat des de http://www.joanteixido.org/doc/lideratgecanvi/lideratge canvi.pdf.

Tejada, J. i altres. (2007a). Formación de formadores. Escenario institucional. Madrid: Thomson.

-(2007b). Formación de formadores. Escenario Aula. Madrid: Thomson.

-(2008). Implicaciones de la evaluación de impacto: una experiencia en un programa de formación de formadores. Grupo CIFO. Bordon, 60 (1), 163-185.

Tejada, J. i Ferrández, E. (2007). La evaluación del impacto de la formación como estrategia de mejora en las organizaciones. Revista Electrónica de Investigación Educativa, 9 (2) Recuperat des de http://redie.uabc.mx/vol9no2/contenidotejada2.html.

-(2012). El impacto de la formación continua: claves y problemáticas. Revista Iberoamericana de Educación, 58 (3) Recuperat des de http://www.rieoei.org/deloslectores/4362Tejada.pdf. 